\title{
The impact of spousal bereavement on hospitalisations: evidence from the Scottish Longitudinal Study
}

\author{
Fu-Min Tseng ${ }^{\mathrm{a}, *}$, Dennis Petrie ${ }^{\mathrm{b}}$, Shaolin Wang ${ }^{\mathrm{a}}$, Colin Macduff $^{\mathrm{c}}, \boldsymbol{\&}$ \\ Audrey Stephen ${ }^{c}$ \\ ${ }^{a}$ Department of Surgery \& Cancer, Centre for Health Policy, Imperial College London, UK \\ ${ }^{\mathrm{b}}$ Melbourne School of Population and Global Health, Centre for Health Policy, University of \\ Melbourne, Australia \\ ${ }^{\mathrm{c}}$ School of Nursing and Midwifery, Robert Gordon University, UK
}

Keywords: spousal bereavement; mortality; hospitalisation; difference-in-differences

Acknowledgements: This paper has benefited from the comments of the members of the SECOB Steering committee. The help provided by Zhiqiang Feng and Lee Williamson of the Longitudinal Studies Centre - Scotland (LSCS) is acknowledged. The LSCS is supported by the ESRC/JISC, the Scottish Funding Council, the Chief Scientist's Office and the Scottish Government. Census output is Crown copyright and is reproduced with the permission of the Controller of HMSO and the Queen's Printer for Scotland. Any opinions expressed in the paper are those of the authors and the authors take responsible for any errors in the paper.

* Correspondence to: Department of Surgery \& Cancer, Centre for Health Policy, Imperial College London, UK. E-mail: f.tseng@imperial.ac.uk

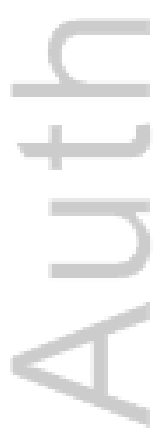

This is the author manuscript accepted for publication and has undergone full peer review but has not been through the copyediting, typesetting, pagination and proofreading process, which may lead to differences between this version and the Version of Record. Please cite this article as doi: $10.1002 /$ hec.3573

This article is protected by copyright. All rights reserved. 


\section{The impact of spousal bereavement on hospitalisations: evidence from the Scottish Longitudinal Study}

Keywords: spousal bereavement; mortality; hospitalisation; difference-in-differences

Conflict of Interest: The authors declare that they have no conflict of interest.

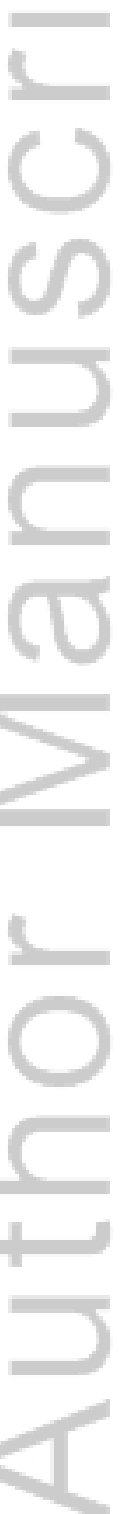

This article is protected by copyright. All rights reserved. 


\section{Introduction}

This paper considers the impact of spousal bereavement on hospital inpatient use for the surviving bereaved. Bereavement is an inevitable event that may cause dramatic changes in health, especially within older populations. Stroebe et al. (2006) and Stroebe et al. (2007) detail the possible pathways from the loss of a loved one to changes in several intermediate outcomes (the direct consequence of bereavement), mainly within the mental health dimension. The extent of changes in outcomes is likely to be heterogeneous across bereavements and the determinants of the extent are complex. When bereavement causes deterioration in mental health, it may also cause deterioration in physical health (Berkman et al., 1986) and reduce investments in health (Simeonova, 2013). Thus, in addition to these intermediate outcomes, bereavement may also cause changes in more distal outcomes, for instance, employment, morbidity, mortality and related medical costs. In countries such as Scotland with statutory national health services, governments finance the majority of medical expenses and thus, the medical costs related to bereavement are often borne by society. Thus, it is important to consider the extent of this extra bereavement-related expenditure when deciding on the level of bereavement-related services and health promotion interventions to be made available which might mitigate some of these negative impacts on well-being and costs.

In this paper we focus on estimating the impact of spousal bereavement on hospitalisations within the National Health Service (NHS) in Scotland. The 14 territorial NHS boards, seven special NHS boards and one public health body administered through NHS Scotland are accountable to Scottish ministers sitting in the devolved Scottish Government. Territorial NHS boards are responsible for the protection and the improvement of their population's health and for the delivery of frontline healthcare services (NHS Scotland, 2015). NHS services are supported by a small private sector (Scottish Independent Hospitals Association, 2016) and substantial third sector input (Scottish Council for Voluntary Organisations, 2016). This paper does not extend to consider the impact on these latter services.

There is a vast literature which has considered the impact of bereavement on mental health. Oswald and Powdthavee (2008) estimate the mental distress measured by GHQ (General Health Questionnaire) score caused by different types of bereavement (death of their father, mother, spouse, sibling, child or friend), using the British Household Panel Survey (BHPS), and find that the death of a spouse results in the largest emotional response as well as the largest loss in life satisfaction. The emotional response related to losing a loved one links to a higher risk of psychosocial stress, depression, and anxiety (Wittstein et al., 2005; Stroebe et al., 2007; Tseng et al., 2017). These symptoms may result in complicated grief where the bereaved have difficulty accepting the death and the intense separation, and 
experience ongoing traumatic distress after lasting six months or longer (Engel, 1962; Bonanno and Kaltman, 2001). About $10 \%$ of the bereaved are estimated to suffer from complicated grief (Zisook and Shear, 2009).

In terms of the pathway from spousal bereavement to hospitalisations, losing a spouse and complicated grief may impact on health-related behaviours, health determinants and preventative healthcare used and informally received from one's spouse (Zisook et al. 1990; Thompson et al. 1984; Prigerson et al. 2001; Simeonova, 2013; Rolden et al. 2014). The elderly are particularly vulnerable with widowers likely to have insufficient caloric intakes due to difficulties in cooking (Koehn, 2001), and widows often suffering greater poverty (Benzeval and Judge, 2001; McGarry and Schoeni, 2005). Therefore it is perhaps not surprising that complicated grief has been found to be associated with negative health consequences such as cancer, cardiac disease, hypertension, suicidality and mortality risk, all of which may lead or be preceded by hospital admissions (Prigerson et al., 1995; Prigerson et al., 1999; Szanto et al., 2006; Espinosa and Evans, 2008; van den Berg et al., 2011). Many studies have examined the effect of spousal bereavement on mortality (Wilson, 2002; Christakis and Iwashyna, 2003). Espinosa and Evans (2008) and van den Berg et al. (2011) demonstrate that spousal bereavement causes increases in mortality and that the effect is strong and instantaneous. A similar finding is shown in Boyle et al. (2011) especially for older women and the effect remains significant for over ten years.

While the bereavement effect on mortality has attracted much attention, few studies have examined the effect on medical utilisation. Simeonova (2013) finds reductions in primary healthcare utilisation due to bereavement and this accounted for a small part of the overall negative effect of widowhood on longevity. Thompson et al. (1984) and Prigerson et al. (2001) show that spousal bereavement causes an increase in the odds of illness but that GP visits decrease rather than increase. However, Goda et al. (2012) find that medical out-ofpocket spending is approximately $29 \%$ higher when an individual becomes widowed. For cancer-related bereavement the rise in mental-health related healthcare utilisation is observable both before and during the first year after their loss (Guldin et al., 2012). Einiö et al (2017) also find that bereaved men were already vulnerable to cardiac problems before they lose a spouse. Rolden et al. (2014) use a 42 months before and 42 months after bereavement approach to look at the change in healthcare expenditure for 6,487 widowed individuals in the Netherlands and find that expenditure increased post bereavement and that hospitalisations were a key driver. The costs of healthcare services as a result of bereavement are of keen interest to researchers in many fields but little research investigates the bereavement impact on utilisation of hospitalisation. Using a long and very large sample from the Scottish population, this paper focuses on exploring the impact of bereavement on both 
the likelihood and length of stay for hospital inpatient admissions and how this evolves preto post-bereavement.

Estimating the impact of bereavement is not straightforward. It is plausible that a couple's underlying health risks are correlated, such that, bereavement is more likely to occur for those couples with poor health. This correlation between the health status of a couple may be partly due to the assortative matching marriage process (Waldron et al., 1996; Cheung, 1998; Murray, 2000), where a couple's health is interlinked because they are likely to match with each other due to some common characteristics, for example, social class, race, education, age, and occupation. In addition, the correlation between the health status of a couple may also exist because the married couple share similar environmental risk factors and life-style behaviours after becoming married, such as, exposure to pollution, diet, exercise and hobbies (Michaud and van Soest, 2008). Thus, the health and mortality of the surviving spouse may be determined not only by the impact of bereavement but also these pre-existing observable and unobservable common health determinants. Therefore, the bereavement effect needs to be disentangled from these other complex factors.

We employ a Cox proportional hazards model to compare the difference in postbereavement survival between the bereaved and non-bereaved before estimating the impact of bereavement on hospital utilisation in terms of inpatient days using data from the Scottish Longitudinal Study (SLS). For inpatient days, these unobserved common factors are controlled for using a difference-in-differences (DiD) model. Propensity score matching methods are used in both models in order to create a non-bereaved group that is more comparable with the bereaved group and thus place a greater weight on the longitudinal experience of those within the non-bereaved group who more closely match the initial characteristics of the bereaved cohort.

This paper is organised as follows: Section 2 introduces the Scottish Longitudinal Study and linked data sets. Section 3 outlines the methods for the propensity score matching, survival analysis and hospital inpatient analysis and section 4 summarizes the results. Finally, section 5 discusses the conclusions and implications for policy.

\section{Data}

\subsection{The Scottish Longitudinal Study data set}

The SLS is an anonymised linkage study including data from the Scottish Census that is conducted every 10 years and collects data on all residents in Scotland (Boyle et al., 2009). 
The initial SLS sample was drawn from the 1991 Census and achieved a representative sample of $5.3 \%$ of the Scottish population based on 20 semi-random birthdays. These individuals are referred to as SLS members and their household members as non-SLS members. A similar sample was then drawn from the 2001 Census. This comprised three cohorts: (1) the SLS members in 1991 if they were still alive and lived in Scotland; (2) the new SLS members who were born or moved into Scotland after 1991; (3) the household members of these SLS members in 2001. Only the SLS members are followed over time such that their data from 1991 and 2001 can be linked. The SLS data provide extensive information on demography, socio-economic status, household composition, housing status, ethnicity, and long-term illness. ${ }^{1}$ At each census point, information is available for both SLS and non-SLS members living within the household.

\subsection{Vital events and health utilisation data set}

The SLS dataset contains census data and other rich administrative data sets such as the vital events data (births, stillbirths, infant deaths, deaths and spousal deaths) and National Health Service Central Register (NHSCR) data (migration in or out of Scotland). NHS data (e.g. cancer registrations and hospital admissions) is also available to be linked to the SLS with appropriate permission from the Privacy Advisory Committee. In this paper, we use SLS member's death records, spousal deaths records, and the Scottish Morbidity Record 1 (SMR01) including information on inpatient admissions. At the time when data access was obtained the vital events as part of the SLS were available for the years 1991 to 2009. These two vital events contain information on month and year of death, month and year of spousal death and age at death. Note that the spousal death records are only available when the SLS member is named as the spouse on a deceased person's death certificate.

The general acute inpatient days and day cases (SMR01), records the dates of admissions and discharges from which inpatient days and the number of treatment episodes per year are calculated for each SLS member. When the dates of admission and discharge are the same, this is treated as one inpatient day for the subsequent analysis.

\subsection{Analytic sample}

In the interest of identifying the impact of spousal bereavement, only the SLS members who met the following criteria are selected into our analytic sample: 1. those who were in their first marriage in 1991; 2. those who resided in a household instead of a communal establishment. This selection criterion excludes the possible influence from previous marriages regardless of whether they were ended by divorce or death, and excludes

\footnotetext{
${ }^{1}$ No actual income information is available. However, the covariates such as age, sex, and social class based on occupation that we control for in the following estimations are tightly correlated with income (Clemens and Dibben, 2014).
} 
those who migrated to Scotland after 1991 as their marital status at this point is unknown. ${ }^{2}$ Moreover, the individuals in care facilities are also excluded from our analysis. The sample size in this first selection is 113,878 . Next, this sample is partitioned into the bereaved group in which the members suffered spousal bereavement during the period of analysis (1991-2009) and the non-bereaved group.

For the hospitalisation analysis, the 113,878 SLS members' linked data are used to create an annual panel data set starting from 1991 until the end of 2009. Only hospital inpatient use and age vary along with years, with the other variables being time-invariant and obtained from the baseline census in 1991. Only baseline information is used to avoid any potential issues in terms of bereavement impacting on the control variables, possible mediators, in our analyses.

\section{Empirical strategy}

Our major goal is to identify the impact of spousal bereavement on hospital inpatient days. The difference-in-differences (DiD) technique comparing the bereaved group with a comparable non-bereaved group before and after spousal (hypothetical) bereavement is firstly used. To compare the change in hospital use pre to post bereavement with the change for the non-bereaved group, a hypothetical bereavement date is generated for each non-bereaved SLS member in order to match the data structure of the bereaved group. For this purpose the one-to-one Nearest-Neighbour Propensity Score Matching approach is employed. This approach pairs the bereaved and non-bereaved individuals that are similar in terms of their propensity score, the probability of being bereaved, estimated by their observable characteristics in 1991. This method reduces the dimensionality of the matching problem (Dehejia and Wahba, 2002). Comparing with only using propensity score matching to identify the bereavement impact, in the process of combining propensity score matching and DiD we are able to control for the unobserved factors constant in each group and the unobserved time-variant factors common to both groups. In addition, given that the bereavement impact may not be constant over time and there may even be some change prebereavement (due to having an ill spouse), we explore how the differences between the bereaved and non-bereaved evolve across both the pre bereavement and post bereavement phases.

\footnotetext{
${ }^{2}$ Non-SLS members are excluded because they do not have information about deaths or hospitalisations available.
} 
The above analysis is also complicated by the differing mortality of the bereaved and non-beavered group such that the hospital analysis estimates the impact of bereavement conditional on survival (Petrie et al. 2011). To complete the picture we also consider the extent of the differences in survival for the bereaved and non-bereaved groups by using a simple Cox proportional hazards model.

The baseline time for the survival model is considered to be the year and month when spousal bereavement or hypothetical bereavement occurs and a variable is generated for each SLS member to indicate the number of months after (hypothetical) bereavement until death or the end of the sample period (2009). It is worth mentioning that it is difficult to identify the impact of spousal bereavement on survival without controlling for unobserved characteristics. However, the pair matching and weighting process is likely to at least partially control for these unobserved effects (by matching observable characteristics it is more likely that differences in unobservable characteristics are smaller). More complicated survival analysis that attempts to control for unobserved common characteristics across the married couple (see van den Berg et al., 2011) are beyond the scope of the current paper because the spouse of most SLS members are not SLS members and therefore not in our sample.

For both these approaches propensity score weights are applied such that the experience of those non-bereaved who more closely match the initial characteristics of the bereaved are weighted more heavily. The method to derive these weights is outlined below.

\subsection{Assigning hypothetical bereavement dates and weights for the non-bereaved}

To assign a hypothetical bereavement date and a weight for the non-bereaved SLS members, the Nearest-Neighbour Propensity Score Matching (NNPSM) and Kernel Propensity Score Matching (KPSM) are implemented (Caliendo and Kopeinig, 2008). The first stage for both matching approaches is to estimate the probability of becoming bereaved as shown in Eq. (1):

$$
\text { (1) } \operatorname{Prob}(S B=1 \mid X)
$$

where $S B$ is a bereavement indicator which is 1 if the member is in the bereaved group and 0 , otherwise. $X$ is a covariate vector comprising of the member's baseline characteristics in 1991 and includes sex, age, race, education, social class, long-term illness and spouse's age in 1991. The predicted probability that each SLS member would have become bereaved is their propensity score.

The one-to-one NNPSM is employed to match a non-bereaved member to his/her closest bereaved member (i.e. their characteristics in 1991 suggested that they had similar chances of becoming a bereaved member) using the propensity score predicted from the 
Logit regression. For the non-bereaved the bereavement date of their matched bereaved member is taken as their hypothetical bereavement date. Some members including the bereaved and the non-bereaved are unmatched (1,511 (10\%) bereaved members and 9,347 (10.6\%) non-bereaved members) due to non-response (missing/edited) 1991 covariates. These unmatched members are excluded from our analytic sample. In addition, the matched non-bereaved members whose time (month and year) of hypothetical bereavement falls later than their time of death are also excluded from our analyses $(8,310 \text { excluded })^{3}$. In addition from the matched non-bereaved members who died within the same month and year as their hypothetical bereavement, half are randomly excluded (65 excluded) as it is assumed half would have died before their hypothetical bereavement date. Finally, the total number of members selected is 94,710 including 15,007 bereaved members and 79,703 non-bereaved members.

While the non-bereaved cohort presents a possible comparison group for the bereaved, there may be reasons, other than the impact of the bereavement itself, why their longitudinal experience in terms of mortality and healthcare utilisation may differ from the bereaved group. In order to create a more comparable non-bereaved group the KPSM is used to generate a weight for each non-bereaved member in terms their similarity to the bereaved cohort given their baseline (1991) characteristics. The propensity score obtained from the Probit regression is used to compute the weight shown in Eq. (2) (Jalan and Ravallion, 2003):

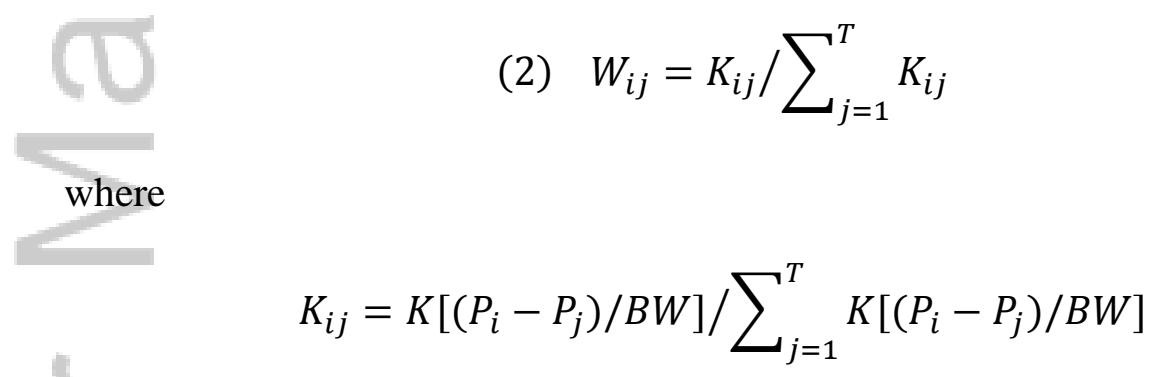

where $W$ is a weight computed by a normal kernel function $K$ of the difference in the propensity scores $P$ of the bereaved member $i$ and the non-bereaved member $j$. $T$ is the total number of the non-bereaved. $B W$ is the optimal bandwidth parameter proposed in Silverman (1986). While the bereaved are all given a weight of 1 in the subsequent analysis, those non-

\footnotetext{
${ }^{3}$ We consider the non-bereaved group as a control group under the assumption that ex ante "by chance" they could have become bereaved at some point during our observation window (though in fact they were lucky enough not to). However for those who themselves died early in our observation window it is less likely that we could have observed them experiencing spousal bereavement (because to experience spousal bereavement they need to outlive their spouse). In addition these non-bereaved individuals whose hypothetical bereavement is predicted to occur after their death are dropped because they do not have information post- (hypothetical) bereavement and including them would bias the result because they are less likely to be included in the bereaved cohort due to their shorter time at risk of bereavement compared with those who survive for longer.
} 
bereaved who more closely match the bereaved cohort in terms of their characteristics in 1991 are given a higher importance weight. Given the large sample of bereaved and nonbereaved individuals and the large component of randomness involved in spousal bereavement we expect most individuals to be within the common support - for a bereaved person there is a similar person who did not become bereaved and vice versa. Thus in our primary analysis we include all individuals and conduct a sensitivity analysis by redoing the analysis only considering those within the common support. We also plot the Kernel densities of the propensity scores of the bereaved and non-bereaved to evaluate the extent of the common support.

\subsection{Estimation}

\subsubsection{Estimating the differences in survival}

We use the weighted Cox proportional hazards model with the weights generated by KPSM to estimate the difference in survival between the bereaved and non-bereaved. To control for unobserved common mortality factors within a couple, the indicators of long-term illness in the entry year (1991) and average inpatient days per year before (hypothetical) bereavement are used. ${ }^{4}$ These provide proxies for health status prior to bereavement and, thus, it is plausible that they are highly correlated with unobserved common spousal health determinants. The model is as Eq. (3):

$$
\text { (3) } h_{i}(t)=h_{0}(t) \exp \left(\rho_{1} S B_{i}+W_{i}^{\prime} \rho\right)
$$

where $h_{i}(t)$ is the hazard rate of member $i$ at time $t$ after (hypothetical) spousal bereavement. $h_{0}(t)$ is the unspecified baseline hazard function. $S B$ is the bereavement indicator and $\exp \left(\rho_{1}\right)$ gives the mortality ratio between the bereaved and the non-bereaved. $W_{i}$ is a vector of covariates including the indicator of long-term illness in 1991, the average annual inpatient days prior to (hypothetical) spousal bereavement, sex, education, ethnicity, social class and age and age squared in the year becoming bereaved. The former two variables are used as proxies to control for those unobserved common factors that influence the health status of both the bereaved individual and their deceased spouse. $\rho$ is a coefficient vector of the covariates.

\subsubsection{Estimating the impact on hospitalisations}

Next we outline the DiD framework used to estimate the impact of spousal bereavement on hospitalisations conditional on survival. As mentioned earlier the health

\footnotetext{
${ }^{4}$ Espinosa and Evans (2008) run a series of Cox proportional hazards models beginning with only the widowhood indicator and progressively increase the number of covariates. If the estimated bereavement effect remains stable with the increase in covariates, this implies that widowhood is uncorrelated with the observed covariates. It is plausible that observed and unobserved covariates are positively correlated and thus, the bereavement effects are not fully capturing unobserved factors.
} 
status of a couple may be highly correlated due to both observed and unobserved factors such that those with a high risk of hospitalisation may be more likely to become bereaved. The DiD framework is able to control for these unobserved time invariant factors that exist in each group and these unobserved time variant factors that commonly exist in both groups to isolate the impact of spousal bereavement on hospitalisations. It eliminates the time constant factors in the bereaved group and controls for the time-variant factors not related to bereavement by using the longitudinal experience of the weighted non-bereaved group as a control. This relies on the longitudinal experience of the weighted non-bereaved group providing a reasonable counterfactual for the expected longitudinal experience of the bereaved group had they not become bereaved. Because bereavement is non-random the propensity score weighting approach is used to place greater importance on the longitudinal experience of those non-bereaved who had similar initial observable characteristics as the bereaved and thus create a "comparable" non-bereaved group. Using a propensity weighted approach combined with a DiD approach is likely further minimise potential bias resulting from the assumptions within both strategies being violated. We employ this strategy with the created panel data set to identify the impact of spousal bereavement on the inpatient days used conditional on survival.

The estimated equation is given in Eq. (4):

$$
\text { (4) } H_{i t}=\alpha_{0}+\alpha_{1} S B_{i t}+\alpha_{2} \text { Post }_{i t}+\alpha_{3} S B_{i t} \cdot \text { Post }_{i t}+X_{i t}^{\prime} \alpha+\varepsilon_{i t}
$$

where $H_{i t}$ is the utilisation of inpatient days for member $i$ in year $t$. SB denotes the bereaved group. Post indicates post-bereavement with 1 given to post-bereavement years and 0 , otherwise. SB.Post is the interaction term of both indicators. $X_{i t}$ is a vector of covariates including age, ethnicity, and dummies for long-term illness in 1991, sex, ethnicity, and social class. $\alpha$ is a vector of coefficients that represent the relationship between controlling factors $(X)$ and utilisation. $\varepsilon$ is the stochastic error term. $\alpha_{3}$ is of particular interest as it represents the estimated impact of spousal bereavement on annual inpatient days.

\subsubsection{Two-Part Model}

In many cases individuals experienced no annual inpatient days. Thus, due to this truncated nature of the data, the Two-Part Model (2PM) is employed to estimate the number of inpatient days (Jones, 2000). The first part (Eq. (5)) estimates the probability of any hospitalisation within each year.

$$
\text { (5) } \begin{aligned}
& P\left(y_{i t}^{*}=1 \mid X\right)=\emptyset\left(X_{i t}^{\prime} \gamma\right) \\
&\left\{\begin{array}{l}
y_{i t}^{*}=1 \\
y_{i t}^{*}=0
\end{array} \text { if } y_{i t}>0\right. \\
&
\end{aligned}
$$


where $y_{i t}$ denotes the number of inpatient days of member $i$ in year $t$ and $\varnothing$ is the cumulative density function of the standard normal distribution. The equation in the second part (Eq. (6)) estimates the number of inpatient days only considering those members who have at least 1 inpatient day. The natural logarithm of inpatient days is used due to the skewed nature of the data.

$$
\text { (6) } \log \left(y_{i t}\right)=X_{i t}^{\prime} \theta+\epsilon_{i t} \quad y_{i t}>0
$$

Finally, the expected number of inpatient days is calculated using the probability obtained from the first part multiplied by the estimated inpatient days obtained from the second part with 'smearing' of the errors applied at the second part to account for the non-linear functional form (Duan et al., 1983). The weighted population-averaged (PA) estimations with the weights generated by KPSM are used in 2PM. Unlike a random-effects model, the PA model need not fully specify the distribution of the population in terms of their individual effects as the PA model focuses only on the marginal distribution. For the binary outcome, the coefficient of the bereavement indicator within the PA model relates to the probability of an average individual who is bereaved being hospitalised compared to the probability of an average individual who is non-bereaved being hospitalised. With continuous outcomes, the coefficients of population-averaged estimation are often very close to those of random-effects estimation (Neuhaus et al., 1991).

\subsubsection{The evolution of hospitalisation differences between the bereaved and non- bereaved}

The above DiD framework considers that the bereaved and non-bereaved groups differ by some fixed amount pre-bereavement and bereavement has a constant impact post bereavement regardless of the years prior or post. We now allow for a more flexible model which captures the evolution of the differences between the bereaved and comparable nonbereaved cohort both pre-bereavement and post-bereavement. In particular, we wish to examine the extent to which the probability of any hospitalisation within each year and inpatient days may have increased or decreased prior to the bereavement event for the bereaved group (perhaps due to having a sick spouse) and how the bereavement impacts themselves change post-bereavement. Therefore, we use Eq. (7) to regress both outcomes separately with the same regressors but where the log inpatient days are conditional on hospitalisation.

$$
\text { (7) } T_{i t}=X_{i t}^{\prime} \beta+W_{i t}^{\prime} \delta+D_{i t}^{\prime} \rho+\epsilon_{i t}
$$

where $T$ presents a dichotomous variable with value 1 indicating hospitalisation or log inpatient days. $\beta$ presents a vector of coefficients corresponding to controlling factors $(X)$. $W_{i t}$ is a vector of 16 dummy variables indicating 7 years prior to bereavement year, bereavement 
year, 7 years after bereavement year, and more than 7 years after bereavement year (such that the reference category is more than 7 years prior to bereavement). $D_{i t}$ is a vector comprising the interaction terms of each dummy variable in vector $W_{i t}$ and $S B . \delta$ and $\rho$ are vectors of coefficients corresponding to $W$ and $D$, respectively. The coefficients of interaction terms represent the differences in the probability of hospitalisation and inpatient days between the bereaved and non-bereaved across from 7 years before bereavement year to more than 7 years after bereavement compared with the difference more than 7 years prior to bereavement. A panel Probit model is used to regress the dichotomous indicator of hospitalisation and a panel OLS model is employed to regress the log inpatient days.

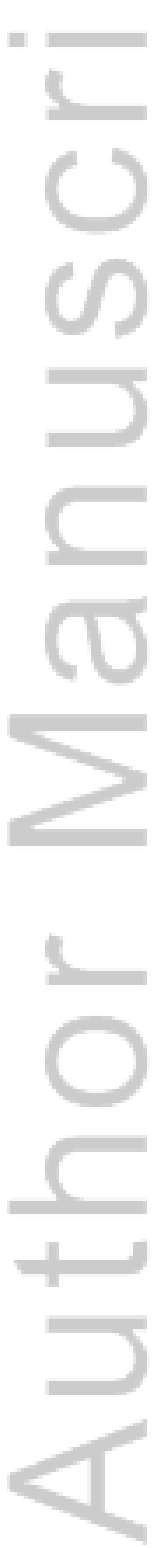




\subsubsection{Uncertainty}

Given the multiple estimation stages the standard errors in all aforementioned estimations are derived by the bootstrapping method. The bootstrapping process derives the standard errors based on sampling with replacement at the individual level from the whole sample and re-running the whole analysis including propensity scoring matching and propensity score weighting using Monte Carlo simulation giving a nonparametric estimate of the underlying error distribution. This means that it captures the uncertainty involved in all steps of the analysis (Freedman and Peters, 1984).

\subsubsection{Sensitivity and heterogeneity of the impact of bereavement}

In addition we consider a sensitivity analysis where we exclude all observations not on the common support from the propensity score matching (those with a very high chance of bereavement in our sample window where there does not exist non-bereaved people with similar characteristics). We also conduct subgroup analyses according to age $(<75$ and $\geq 75$ ) and baseline household size ( $=2$ and $>2)$. These allow us to investigate whether the bereavement effect differs depending on the bereaved's age and whether it differs by the likely composition of the household post bereavement where for initial households of size two the bereaved spouse may be highly likely to be living alone post bereavement. In addition we restrict the bereaved group to those where the spouse of individuals died from an accident or violence and then in a separate analysis to those where the spouse died from cancer. The deaths from accidents and violence may be more likely to be exogenous and more sudden while the deaths from cancer may be related to underlying risk factors and may be preceded by a lengthy illness stage. These causes of death are based on those listed in International Classification of Diseases Version 9 (ICD-9). ${ }^{5}$

\section{Results}

\subsection{Descriptive statistics}

We begin with a description of the sample under consideration. Table 1 presents the mean characteristics of the bereaved, non-bereaved, and weighted non-bereaved samples. The bereaved members are approximately $15.89 \%$ of the total sample. Next we consider the numbers that become bereaved (or hypothetically bereaved) within four time periods and the subsequent numbers of these who are observed to have died before the end of 2009. The mortality rate of the bereaved group is seen to be higher than that of the non-bereaved group in each time period.

\footnotetext{
${ }^{5}$ The types of cancers selected are malignant neoplasms with codes 140-195, 196-198, 199, and 200-208.
} 
As for demographic and socio-economic characteristics, the bereaved group has approximately $30 \%$ more females, contrasting with the non-bereaved group which has about $2.1 \%$ more males. ${ }^{6}$ The education level of the bereaved group is lower than that of the nonbereaved group with $90.37 \%$ of the bereaved cohort reporting no higher degrees or qualifications compared to $81.61 \%$ for the non-bereaved cohort. Potentially related to education levels are the differences of social class where the bereaved have $14.79 \%$ with managerial and technical occupations and $38.6 \%$ in the 'others' classification compared to the non-bereaved with $24.7 \%$ and $13.18 \%$ respectively. ${ }^{7}$ The bereaved, on average, are older than the non-bereaved by 16 years. The average post- (hypothetical) bereavement duration observed is about 86.13 months for the bereaved and 90.37 months for the non-bereaved, which indicates the maximal months of data available for each SLS member after (hypothetical) spousal bereavement until death or the end of the sample period (Dec 2009). With respect to inpatient days, the bereaved have more utilisation than the non-bereaved and the utilisation trends upwards in both groups as they age.

Column 3 shows the summary statistics for the weighted non-bereaved group, who are our comparison group for the subsequent analysis (the kernel estimation is shown in Table A1). After weighting, the differences in all characteristics, apart from the postbereavement duration, between the bereaved and non-bereaved groups diminish and the weighted non-bereaved group, in general, appears to have similar initial characteristics as the bereaved group.

We also present a figure of the distribution of predicted propensity scores (chance of not being bereaved during the period) for both groups (Figure A1) as generated by the logit regression (Table A1 provided the logit results). One can see that the propensity scores of most non-bereaved are greater than 0.9 , meaning a large proportion of the non-bereaved exante had an extremely high chance of not losing their spouse over the period given their baseline characteristics. However, there are still some non-bereaved who ex-ante had a higher change of bereavement with the figure showing the interval overlapped by the distributions of propensity score of the bereaved and non-bereaved groups is between 0.25 and 1 and that the individuals not in the overlapping region are a very small minority of bereaved people who ex-ante had an extremely high chance of bereavement (very low chance of non-bereavement) during the period. This suggests that based on the observable characteristics bereavement is still a highly random event - there are non-bereaved people with similar characteristics with each bereaved person and vice versa.

\footnotetext{
${ }^{6}$ Males have a higher mortality rate meaning that the females are more likely to be left as the bereaved.

${ }^{7}$ The category of 'others' includes inadequately described occupations and occupation not stated.
} 


\subsection{Survival analysis}

In terms of the survival analysis, the bereavement indicator, age, sex, education dummy variables, social class dummy variables in skilled manual occupations, unskilled occupations and others, the long-term illness indicator, and the average inpatient days per year prior to bereavement have significant $(p<0.01)$ associations with the mortality rate (Table 2). The bereaved group has a mortality rate that is $19.2 \%$ higher than the weighted non-bereaved group after controlling for other factors. The Kaplan-Meier survival functions based on the smoothed estimated survival probability (Figure 1) show that in the postbereavement period the survival probability of the bereaved is lower than that of the weighted non-bereaved with about $10 \%$ less of the bereaved expected to be alive after 18 years compared if they had not been bereaved. ${ }^{8}$

\subsection{Hospitalisation}

Before showing the primary result, we present the more detailed evolution of differences in probability and days of hospitalisation between the bereaved and non-bereaved across 15 years ( 7 years pre-bereavement, the bereavement year, and 7 years postbereavement) conditional on survival. Figure 2 shows the bereaved have very similar probabilities of being hospitalised than the comparable non-bereaved in the years before losing spouse with all these small differences before the bereavement year being not significant $(p>0.05)$. However, significant $(p<0.05)$ differences are observed in the bereavement year and afterwards apart from the fifth year which is not significant but where the estimated difference is still sizeable (Column 1 in Table A2). In the year of bereavement the probability of being hospitalised is about $1 \%$ higher for the bereaved group compared to the non-bereaved and about $2 \%$ higher in all later years, implying that the bereaved are more likely to be hospitalised after losing their spouse. When we spilt this by gender a similar effect size and pattern is observed where for males, the differences are significant $(p<0.05)$ after bereavement year (excluding the fifth year after bereavement) and a similar finding is observed for females.

Once individuals are admitted to hospital, the differences in hospitalisation days between both groups are not significant $(p>0.05)$ whether before or after bereavement (Column 1 in Table A3). Though not significant, in general, in the post bereavement years the bereaved group have slightly longer hospital stays than the non-bereaved group compared to the pre-bereavement years. A similar finding is observed for females (Column 3 in Table A3).

\footnotetext{
${ }^{8}$ The kernel function here is Gaussian and bandwidth is the width that would minimize the mean integrated square error.
} 
For males (Column 2 in Table A3), however, the bereaved have about $17.6 \%$ more hospitalisation days than the non-bereaved in the third year after losing a spouse $(p<0.05)$.

Table 3 presents the results of the DiD Two-Part Model for hospitalisation, conditional on survival where the pre-bereavement period and post-bereavement periods are now grouped together. From the spousal bereavement (SB) coefficient we see that in the prebereavement period there are only small non-significant differences between the bereaved and weighted non-bereaved groups. From the post-bereavement variable (Post) we see that for the weighted non-bereaved group there is a significant increase in the probability of being hospitalised and the number of inpatient days per year once hospitalised over time (i.e. moving from the pre to post hypothetical bereavement period). From the interaction term of SB and Post we see that spousal bereavement has a significant $(p<0.01)$ impact on the probability of hospitalisation and inpatient days over and above the increase observed in the weighted non-bereaved group. ${ }^{9}$ We calculate the estimated increase in inpatient days caused by the bereavement impact using the estimations presented in Table 3. In particular we consider the average predicted in-patient days for the bereaved and non-bereaved groups and then consider how much lower the bereaved group inpatient days would have been had they not become bereaved at that point. These estimated combined marginal effect results are shown in Table 4. The average inpatient days for individuals who are bereaved is estimated to be 0.69 days per person per year and the average is 0.18 days for individuals who are nonbereaved. The gap between the bereaved individual and the non-bereaved individual is 0.51 days per person per year, among which the spousal bereavement impact contributes an estimated 0.24 days which is being driven both by an increase in the probability of being admission in any year and the increase in the number of days they are staying in hospital each year. The remaining differences are estimated to be due to the other observed and fixed unobserved differences between the two groups.

When we consider the analysis with only the sample within the common support from the propensity score matching the conclusions are unchanged (see Table A4 for the common support results).

Table 5 presents the heterogeneity in the impact of bereavement across a number of subgroups. A significant $(p<0.05)$ bereavement impact is observed in the probability and inpatients days in four subgroups. The increase in average inpatient days attributed to bereavement is much greater for the older subgroup ( 0.61 days) than for the younger subgroup (0.08 days) and greater for the bereaved in smaller households who may live alone after bereavement ( 0.33 days) than for the bereaved from bigger households $(0.11$ days $)$. For

\footnotetext{
${ }^{9}$ The coefficients of the second part estimation refer to the change of percentage in inpatient days for 1 unit changes in the explanatory variables.
} 
bereavement where the cause of death is cancer, the coefficients for the first part and second part estimations are 0.15 and 0.12 , respectively. Both coefficients are significant $(p<0.05)$ and slightly higher than those for the full bereaved sample. For those bereaved due to an accident or violence as the cause of death, the coefficients for the first and second part estimations are 0.15 and 0.27 , respectively, and are also slight higher than those coefficients for the full bereaved sample, though they are not significantly different from zero for this subgroup $(p>0.05)$. The non-significance is attributable to the small sample size of the bereaved due to this cause $(N=117)$ and thus large standard errors.

\section{Conclusion}

This paper attempts to estimate the impact of spousal bereavement on hospital inpatient days for a 15,007 semi-random sample of those bereaved in Scotland between 1991 to 2009. We employed a difference-in-differences strategy to identify the bereavement impact on inpatient hospitalisations. To complete the picture, we used a simple survival analysis to compare the post- (hypothetical) bereavement survival duration of the bereaved and the nonbereaved. Before conducting difference-in-differences and survival analyses, propensity score matching methods were used to generate a more comparable comparison group. This paper draws three main conclusions.

First, after controlling for common factors between a surviving spouse and the deceased spouse, we find that the bereaved have a $19.2 \%$ higher mortality rate than the nonbereaved. The finding of higher mortality hazard for the bereaved is consistent with previous studies (Espinosa and Evans, 2008; van den Berg et al., 2011; Boyle et al., 2011; Simeonova, 2013). Boyle et al. (2011) use the same data set and model as well as a similar analytic period to estimate the effect of spousal bereavement controlling for three selection effects (shared socioeconomic background, shared health-related life style and common access to healthcare resources, and shared attitudes to risk). The mortality rate is higher for the bereaved than the non-bereaved by $36 \%$ to $64 \%$ after the covariates (age, qualification, ethnicity, social class, self-reported health status, household size, tenure, car availability, presence of central heating, and the Carstairs score) are controlled. The mortality rate for the bereaved, on average, is estimated to be approximately $38 \%$ (the average of all causes) higher than the non-bereaved. This is double our estimated hazard ratio. This might be attributed to three reasons. First, a difference is between our sample and Boyle's sample. We focus on the survival rate in the post-bereavement period so that the non-bereaved who died before their hypothetical bereavement date $(N=8,310)$ are excluded from our analysis whereas those individuals were included in Boyle et al. (2011). Second, we control for the average level of hospitalisations 
prior to the bereavement event. Third, we implement a weighted survival analysis using the propensity weight. This has a large impact on our results. When we implement our estimation without the propensity score weight, the hazard ratio becomes 1.29 from 1.19 and much closer to the Boyle et al. (2011) result. Which estimate is more accurate depend on whether matching on observables in 1991 has reduced the correlation of important unobservables between the groups.

Second, for the bereaved while they were alive, they were more likely to be admitted to hospital and spend more days in hospital each year when they are admitted. This is consistent with our expectation that the bereaved are more vulnerable than the non-bereaved. A plausible explanation is that mental health is a bridge between bereavement and physical health. When bereavement occurs, individuals may experience mental health issues if they fail to cope with the bereavement. Long-term exposure to mental health issues may result in a deterioration of physical health which leads to hospitalisation if people fail to undertake basic tasks which maintain good health, such as exercise, diet and engagement with primary and preventative health care. Two reasons may explain the observation that the bereaved are likely to spend more days in hospital. First, they may be more likely to be suffering from mental health issues as well as physical problems which complicates their treatment and discharge. This may cause an increase in the time spent in hospital. Second, more hospitalisation days may be related to the bereaved having complex health and social care needs and living alone or having less family members available to support them post hospitalisation (Ou et al., 2009). Our subgroup analysis also supports this speculation where we find the bereaved from smaller initial households were more likely to have more inpatient days.

Finally, with our data, the average inpatient days for the bereaved group are almost four times those for the non-bereaved group. The impact of spousal bereavement is estimated to contribute 0.24 days, approximately $49 \%$ of the gap in average inpatient days between the two groups with the remaining gap likely due to the selection effects in terms of the bereaved more likely to be sicker to being with. The increment of inpatient days occupies a large share of wider financial costs for health services caused by spousal bereavement (Birrell et al., 2013; Stephen et al., 2014).

In conclusion, the impact of spousal bereavement on mortality and hospital inpatient admission is substantial and further research is needed to explore the extent to which bereavement support services could reduce these impacts and costs. Further research on the possible decay of the bereavement impact and on the extent to which the impact of bereavement depends on the cause of death, social support and other possible determinants would also be beneficial as it would allow interventions to be targeted on those who are likely 
to need the greatest support. Large datasets with long-term follow such as the SLS are especially useful to answer these questions.

\section{Reference}

van den Berg, G.J., Lindeboom, M., and Portrait, F. (2011). Conjugal bereavement effects on health and mortality at advanced ages. Journal of Health Economics 20: 774-794.

Berkman, L.F., Berkman, G.S., Kasl, S., Freeman, D.H., Leo, L., Ostfeld, A.M., Cornoni, J. and Brody, J.A. (1986). Depressive symptoms in relation to physical health and functioning in the elderly. American Journal of Epidemiology 124(3): 372-88.

Bezeval, M. and Judge, K. (2001). Income and health: the time dimension. Social Science \& Medicine 52: 1371-90.

Birrell, J., Corden, A., Macduff, C., Newsom, C., Petrie, D.J., Schut, H., Skar, S., Stephen, A.I., Tseng, F.M., Wang, S., and Wilson, S. (2013) The Socio-economic Cost of Bereavement in Scotland. Available from The Scottish Grief and Bereavement Hub: http://hdl.handle.net/10059/1561

Boyle, P.J., Feijten, P., Feng, Z., Hattersley, L., Huang, Z., Nolan, J. and Raab, G. (2009). Cohort profile: The Scottish Longitudinal Study (SLS). International Journal of Epidemiology 38: 385-92.

Boyle, P.J., Feng, Z. and Raab, G.M. (2011). Does widowhood increase mortality risk? Testing for selection effects by comparing causes of spousal death. Epidemiology 22: 1-5

Caliendo, M. and Kopeinig, S. (2008). Some practical guidance for the implementation of propensity score matching. Journal of Economic Surveys 22(1): 31-72.

Cheung, Y.B. (1998). Can marital selection explain the difference in health between married and divorced people? From a longitudinal study of a British birth cohort. Public Health 112(2): 113-7.

Christakis, N.A. and Iwashyna, T.J. (2003). The health impact of health care on families: a matched cohort study of hospice use by decedents and mortality outcomes in surviving, widowed spouses. Social Science \& Medicine 57: 465-75.

Clemens, T. and Dibben, C. (2014). A method for estimating wage, using standardised occupational classifications, for use in medical research in the place of self-reported income. BMC Medical Research Methodology 14: 59. doi:10.1186/1471-2288-14-59 
Dehejia, R.H. and Wahba, S. (2002). Propensity score-matching methods for nonexperimental causal studies. The Review of Economics and Statistics 84: 151-61.

Duan, N., Manning Jr., W. G., Morris, C. N., \& Newhouse, J. P. (1983). A Comparison of Alternative Models for the Demand for Medical Care. Journal of Business \& Economic Statistics, 1: 115-26.

Einiö, E., Moustgaard, H., Martikainen, P. and Leinonen, T. (2017). Does the risk of hospitalisation for ischaemic heart disease rise already before widowhood? Journal of Epidemiology \& Community Health Published Online First: 24 February. doi: 10.1136/jech-2016-207987.

Espinosa, J. and Evans, W.N. (2008). Heightened mortality after the death of a spouse: marriage protection of marriage selection? Journal of Health Economics 27: 1326-42.

Freedman, D.A. and Peters, S.C. (1984). Bootstrapping a regression equation: some empirical results. Journal of American Statistics Association 79: 97-106.

Goda, C.S., Shoven, J.B., and Slavov, S.N. (2012). Does widowhood explain gender differences in out-of-pocket medical spending among the elderly? Journal of Health economics, forthcoming, doi:10.1016/j.jhealeco.2012.10.011.

Guidin, M., Jensen, A.A., Zachariae, R., and Vedsted, P. (2012). Health care utilization of bereaved relatives of patients who died from cancer. A national population-based study. Psycho-Oncology forthcoming, DOI: 10.1002/pon.3120.

Jalan, J. and Ravallion, M. (2003). Estimating the benefit incidence of an antipoverty program by propensity-score matching. Journal of Business and Economic Statistics 21: 19-30.

Jones, A.M. (2000). Health econometrics, Handbook of Health Economics, in: Culyer, A.J. and Newhouse, J.P. Handbook of Health Economics, edition 1, volume 1, chapter 6, pages 265-344 Elsevier.

Koehn, S. (2001). Food for life/back to the table. Report of Research Findings.

McGarry, K. and Schoeni, R.F. (2005). Widow(er) poverty and out-of-pocket medical expenditures at the end of life. Journal of Gerontology B60(3): S160-8.

Michaud, P. and van Soest, A. (2008). Health and wealth of elderly couples: causality tests using dynamic data and panel models. Journal of Health Economics 27(5): 1312-25. 
Murray, J.E. (2000). Marital protection and marital selection: evidence from a historicalprospective sample of American men. Demography 37(4): 511-21.

Neuhaus, J.M., Kalbfleisch, J.D., and Hauck, W.W. (1991). A comparison of cluster-specific and population-averaged approaches for analysing correlated binary data. International Statistical Review 59: 25-35.

NHS Scotland. (2015). Scotland's Health on the Web: About NHS Scotland. Edinburgh: NHS Scotland. Available from: http://www.scot.nhs.uk/about-nhs-scotland/ [Accessed 10th August 2016]

Oswald, A. and Powdthavee, N. (2008). Death, happiness, and calculation of compensatory damages. Journal of Legal Studies 37(S2): S217-51.

Ou, L., Young, L., Chen, J., Santiano, N., Baramy, L. and Hillman, K. (2009). Discharge delay in acute care: reasons and determinants of delay in general ward patients. Australian Health Review 33: 513-21.

Petrie, D., Paul A. and Gerdtham, U-G. (2011) Accounting for the dead in the longitudinal analysis of income-related health inequalities. Journal of Health Economics 30: 1113 23.

Prigerson, H.G., Maciejewski, P.K., Reynolds, C.F. $3^{\text {rd }}$, Bierhals, A.J., Newsom, J.T., Fasiczka, A., Frank, E., Doman, J. and Miller, M. (1995). Inventory of complicated grief: a scale to measure maladaptive symptoms of loss. Psychiatry Research 59: 6579.

Prigerson, H.G., Shear, M.K., Jacobs, S.C., Reynolds, C.F. $3^{\text {rd }}$, Maciejewski, P.K., Davidson, J.R., Rosenheck, R., Pilkonis, P.A., Wortman, C.B., Williams, J.B., Widiger, T.A., Frank, E., Kupfer, D.J. and Zisook, S. (1999). Consensus criteria for traumatic grief: a preliminary empirical test. British Journal of Psychiatry 174: 67-73.

Prigerson, H., Silverman, G.K., Jacobs, S., Maciejewski, P., Kasl, S.V., and Rosenheck, R. (2001). Traumatic grief, disability and the underutilization of health services: a preliminary look. Primary Psychiatry 8: 61-9.

Rolden, H.J.A., van Bodegom, D. and Westendrop, R.G.J. (2014). Changes in health care expenditure after the loss of a spouse: data on 6,487 older widows and widowers in the Netherlands. PLoS ONE 9(12): e115478. Doi:10.1371/journal.pone.0115478.

Scottish Council for Voluntary Organisations (SCVO). (2016). Scottish third sector statistics. SCVO. Available from: http://www.scvo.org.uk/news-campaigns-andpolicy/research/scvo-scottish-third-sector-statistics/ [Accessed 10th August 2016]

This article is protected by copyright. All rights reserved. 
Scottish Independent Hospitals Association. (2016). London: Association of Independent Healthcare Organisations. Available from:

http://aiho.org.uk/index.php?option=com_sobipro\&sid=4\&Itemid=1174 [Accessed 10th August 2016]

Silverman, B.W. (1986). Density estimation for statistics and data analysis. London: Chapman and Hall.

Simeonova, E. (2013). Marriage, bereavement and mortality: the role of health care utilization. Journal of Health Economics 32: 33-50.

Stephen, A.I., Macduff, C., Petrie, D.J, Tseng, F.M., Schut, H., Skår, S., Corden, A., Birrell, J., Wang, S., Newsom, C., and Wilson, S (2014). The economic cost of bereavement in Scotland. Death Studies 39: 151-7.

Stroebe, M.S., Folkman, S., Hansson, R.O., and Schut, H. (2006). The prediction of bereavement outcome: development of an integrative risk factor framework. Social Science \& Medicine 63: 2440-51.

Stroebe, M.S., Schut, H., and Stroebe, W. (2007). Health outcomes of bereavement. Lancet 370: 1960-73.

Szanto, K., Sgear, M.K., Houck, P.R., Reynolds, C.F. $3^{\text {rd }}$, Frank, E., Caroff, K. and Silowash, R. (2006). Indirect self-destructive behaviour and overt suicidality in patients with complicated grief. Journal of Clinical Psychiatry 67: 233-9.

Thompson, L.W., Breckenridge, J.N., Gallagher, D., and Peterson, J.A. (1984). Effects of bereavement on self-perceptions of physical health in elderly widows and widowers. Journal of Gerontology 39: 309-14.

Tseng, F.M., Petrie, G. and Leon-Gonzalez. (2017). The impact of spousal bereavement on subjective wellbeing: evidence from the Taiwanese elderly population. Economics and Human Biology 26: 1-12.

Waldron, H., Hughes, M.E., and Brooks, T.L. (1996). Marriage protection and marriage selection-prospective evidence for reciprocal effects of marital status and health. Social Science \& Medicine 43(1): 113-23.

Wilson, S.E. (2002). The health capital of families: an investigation of the inter-spousal correlation in health status. Social Science \& Medicine 55: 1157-72.

Wittstein, I.S., Thieman, D.R., Lima, J.A.C., Baughman, K.L., Schulman, S.P., Gerstenblith, G., Wu, K.C., Rade, J.J., Bivalacqua, T.J., Champion, H.C. (2005). Neurohumoral 
features of myocardial stunning due to sudden emotional stress. New England Journal of Medicine 352: 539-48.

Zisook, S. and Shear, K. (2009). Grief and bereavement: what psychiatrists need to know. World Psychiatry 8: 67-74.

Zisook, S., Shuchter, S.R. and Mulvihill, M. (1990). Alcohol, cigarette, and medication use during the first year of widowhood. Psychiatric Annals 20: 318-26.

Table 1. SLS member characteristics for those that were married in 1991

\begin{tabular}{|c|c|c|c|}
\hline & (1) & (2) & (3) \\
\hline Variable & Bereaved group & $\begin{array}{c}\text { Non-bereaved } \\
\text { group }\end{array}$ & $\begin{array}{l}\text { Non-bereaved } \\
\text { group (weighted) }\end{array}$ \\
\hline E & Sample size $(\%)$ & Sample size $(\%)$ & Sample size $(\%)$ \\
\hline \multicolumn{4}{|c|}{ Become widow/widower (including hypothetical) } \\
\hline Within 1991-1995 (I) & $3,912(26.11 \%)$ & $14,148(17.84 \%)$ & $4,734(31.60 \%)$ \\
\hline Within 1996-2000 (II) & $4,126(27.54 \%)$ & $20,046(25.28 \%)$ & $4,261(28.45 \%)$ \\
\hline Within 2001-2005 (III) & $3,934(26.26 \%)$ & $23,842(30.07 \%)$ & $3,505(23.39 \%)$ \\
\hline Within 2006-2009 (IV) & $3,008(20.08 \%)$ & $21,256(26.81 \%)$ & $2,480(16.55 \%)$ \\
\hline \multicolumn{4}{|c|}{ Dead by 2009 within each widow/widower group } \\
\hline (I) & $2227(56.93 \%)$ & $3369(23.81 \%)$ & $2612(55.18 \%)$ \\
\hline (II) & $1866(45.23 \%)$ & $2751(13.72 \%)$ & $1622(38.07 \%)$ \\
\hline (III) & $1053(26.77 \%)$ & $1598(6.70 \%)$ & $644(18.37 \%)$ \\
\hline$(\mathrm{IV})$ & $258(8.58 \%)$ & $444(2.09 \%)$ & $138(5.56 \%)$ \\
\hline \multicolumn{4}{|l|}{ Baseline Characteristics 1991} \\
\hline \multicolumn{4}{|l|}{ Sex } \\
\hline Male & $5,279(35.23 \%)$ & $40,489(51.05 \%)$ & $5,915(38.33 \%)$ \\
\hline Female & $9,701(64.77 \%)$ & $38,803(48.95 \%)$ & $9,065(61.67 \%)$ \\
\hline \multicolumn{4}{|l|}{ Education } \\
\hline First degree or higher degree & $468(3.13 \%)$ & $6,302(7.94 \%)$ & $533(3.19 \%)$ \\
\hline Other high qualification & $975(6.51 \%)$ & $8,277(10.44 \%)$ & $1,000(6.38 \%)$ \\
\hline No high degree or qualification & $13,537(90.36 \%)$ & $64,713(81.62 \%)$ & $13,446(90.43 \%)$ \\
\hline \multicolumn{4}{|l|}{ Ethnicity } \\
\hline White & $14,952(99.81 \%)$ & $78,329(98.78 \%)$ & $14,932(99.76 \%)$ \\
\hline Non-White & $30(0.19 \%)$ & $963(1.22 \%)$ & $48(0.24 \%)$ \\
\hline \multicolumn{4}{|l|}{ Social class based on occupations } \\
\hline Professional occupations & $231(1.54 \%)$ & $3,297(4.15 \%)$ & $268(1.60 \%)$ \\
\hline Managerial and technical occupations & $2,215(14.80 \%)$ & $19,587(24.71 \%)$ & $2,256(14.36 \%)$ \\
\hline Skilled non-manual occupations & $2,051(13.70 \%)$ & $15,177(19.12 \%)$ & $2,040(13.19 \%)$ \\
\hline Skilled manual occupations & $1,820(12.13 \%)$ & $14,848(18.74 \%)$ & $1,943(12.57 \%)$ \\
\hline Partly skilled occupations & $1,603(10.69 \%)$ & $10,634(13.43 \%)$ & $1,653(10.86 \%)$ \\
\hline Unskilled occupations & $1,269(8.47 \%)$ & $4,857(6.12 \%)$ & $1,221(8.31 \%)$ \\
\hline Others $^{1}$ & $5,791(38.66 \%)$ & $10,892(13.74 \%)$ & $5,599(39.12 \%)$ \\
\hline Long term illness & $3,208(21.38 \%)$ & $7,231(9.16 \%)$ & $3,183(22.31 \%)$ \\
\hline
\end{tabular}


Age in 1991

\begin{tabular}{ccc}
\hline Mean (Std.) & Mean (Std.) & Mean (Std.) \\
\hline $59.87(11.66)$ & $43.14(13.24)$ & $58.77(13.79)$
\end{tabular}

KPSM Weight ${ }^{2}$

$1.00(0)$

$--$

$0.19(0.30)$

Number of members

$14,980(15.89 \%)$

Mean (Std.)

Mean (Std.)

$\%)$

Mean (Std.)

Post-bereavement duration (months) ${ }^{3}$

$86.13(60.26)$

90.37 (61.16)

$91.96(62.05)$

Average inpatient days

(per person per year)

Within 1991-1995

$1.61(11.91)$

$0.72(7.13)$

$1.93(16.13)$

$2.46(12.60)$

$0.88(6.90)$

$2.30(12.05)$

Within 2001-2005

$3.44(15.34)$

$1.07(8.20)$

$2.60(13.13)$

$4.48(17.79)$

$1.31(8.30)$

$2.79(13.51)$

1. The category of others includes the categories of inadequately described occupation, armed forces, occupation not stated, and no job in last 10 years or aged under 16. 2. The maximized and minimized values of the KPSM weights are 1.699 and 0.029. 3. Refers to months of available data after bereavement. Source: The Scottish Longitudinal Study.

Table 2. Cox Proportional Hazards Estimation (Weighted Regression)

\begin{tabular}{|c|c|c|c|}
\hline $\begin{array}{l}\text { Dep. Var.: Post- (hypothetical) } \\
\text { bereavement duration }\end{array}$ & Coef. & Bootstrap S.E. & Hazard Ratio \\
\hline SB (Spousal Bereavement) & $0.176^{* * * *}$ & 0.030 & $1.192^{* * *}$ \\
\hline Age & $0.227^{* * *}$ & 0.020 & $1.255^{* * *}$ \\
\hline Square of age & $-0.001^{* * *}$ & 0.0001 & $0.999^{* * *}$ \\
\hline Male & $0.462^{* * *}$ & 0.034 & $1.587^{* * *}$ \\
\hline \multicolumn{4}{|l|}{ Ethnicity (re. Non-white) } \\
\hline White & 0.232 & 0.662 & 1.261 \\
\hline \multicolumn{4}{|l|}{$\begin{array}{l}\text { Education (ref. No higher degree or } \\
\text { qualification) }\end{array}$} \\
\hline First degree & $-0.328^{* * *}$ & 0.105 & $0.720^{* * *}$ \\
\hline Other higher qualification & $-0.196^{* * *}$ & 0.066 & $0.822^{* * *}$ \\
\hline \multicolumn{4}{|l|}{ Social class based on occupations (ref. } \\
\hline Professional occupations & 0.063 & 0.126 & 1.065 \\
\hline Skilled non-manual occupations & -0.010 & 0.079 & 0.990 \\
\hline Skilled manual occupations & $0.149^{* *}$ & 0.069 & $1.161^{* *}$ \\
\hline Partly skilled occupations & $0.130^{*}$ & 0.070 & $1.139^{*}$ \\
\hline Unskilled occupations & $0.289^{* * *}$ & 0.081 & $1.335^{* * *}$ \\
\hline Others & $0.341^{* * *}$ & 0.059 & $1.406^{* * *}$ \\
\hline \multicolumn{4}{|l|}{ Proxies for omitted common factors } \\
\hline Long-term illness & $0.305^{* * *}$ & 0.034 & $1.357^{* * *}$ \\
\hline $\begin{array}{l}\text { Average annual inpatient days prior to } \\
\text { bereavement }\end{array}$ & $0.012^{* *}$ & 0.005 & $1.012^{* *}$ \\
\hline Sample size & & 90,751 & \\
\hline
\end{tabular}

$p<0.10,^{* * *} p<0.05,^{* * *} p<0.01$. Source: The Scottish Longitudinal Study.

Table 3. Two-Part Model Estimations (Weighted Regression) 


\begin{tabular}{|c|c|c|c|c|}
\hline & Coef. (Boc & otstrap S.E.) & Coef. (Bo & otstrap S.E \\
\hline SB (Spousal bereavement) & -0.006 & $(0.013)$ & -0.027 & $(0.021)$ \\
\hline Post (Post bereavement) & $0.093^{* * *}$ & $(0.013)$ & $0.260^{* * *}$ & $(0.022)$ \\
\hline SB $*$ Post & $0.109^{* * *}$ & $(0.015)$ & $0.097^{* * *}$ & $(0.029)$ \\
\hline Age & $-0.009^{* * *}$ & $(0.003)$ & $-0.045^{* * *}$ & $(0.004)$ \\
\hline Square of age & $0.0002^{* * *}$ & $(0.00002)$ & $0.001^{* * *}$ & $(0.00004)$ \\
\hline Male & $0.104^{* * *}$ & $(0.016)$ & -0.004 & $(0.021)$ \\
\hline Ethnicity (ref. Non-white) & & & & \\
\hline White & -0.062 & $(0.095)$ & -0.003 & $(0.116)$ \\
\hline $\begin{array}{l}\text { Education (ref. No higher degree or } \\
\text { qualification) }\end{array}$ & & & & \\
\hline First degree & $-0.141^{* * *}$ & $(0.028)$ & $-0.106^{* *}$ & $(0.047)$ \\
\hline Other higher qualification & $-0.064^{* *}$ & $(0.026)$ & $-0.101^{* * *}$ & $(0.036)$ \\
\hline Long-term illness & $0.283^{* * *}$ & $(0.015)$ & $0.251^{* * *}$ & $(0.021)$ \\
\hline $\begin{array}{l}\text { Social class based on occupations ( } r \\
\text { Managerial and technical occupatio }\end{array}$ & & & & \\
\hline Professional occupations & 0.025 & $(0.045)$ & 0.009 & $(0.069)$ \\
\hline Skilled non-manual occupations & -0.022 & $(0.019)$ & -0.032 & $(0.033)$ \\
\hline Skilled manual occupations & 0.012 & $(0.021)$ & $0.065^{* *}$ & $(0.027)$ \\
\hline Partly skilled occupations & 0.031 & $(0.022)$ & $0.058^{* *}$ & $(0.028)$ \\
\hline Unskilled occupations & $0.044^{*}$ & $(0.025)$ & $0.100^{* * *}$ & $(0.034)$ \\
\hline Others & 0.018 & $(0.019)$ & $0.121^{* * *}$ & $(0.032)$ \\
\hline Year dummy variables are controlled & & Yes & & Yes \\
\hline Sample size & 1,70 & 8,584 & & 7,494 \\
\hline
\end{tabular}

${ }^{*} p<0.10,{ }^{* *} p<0.05,{ }^{* * * *} p<0.01$. Source: The Scottish Longitudinal Study.

Table 4. Two-Part Estimations (Weighted Regression)

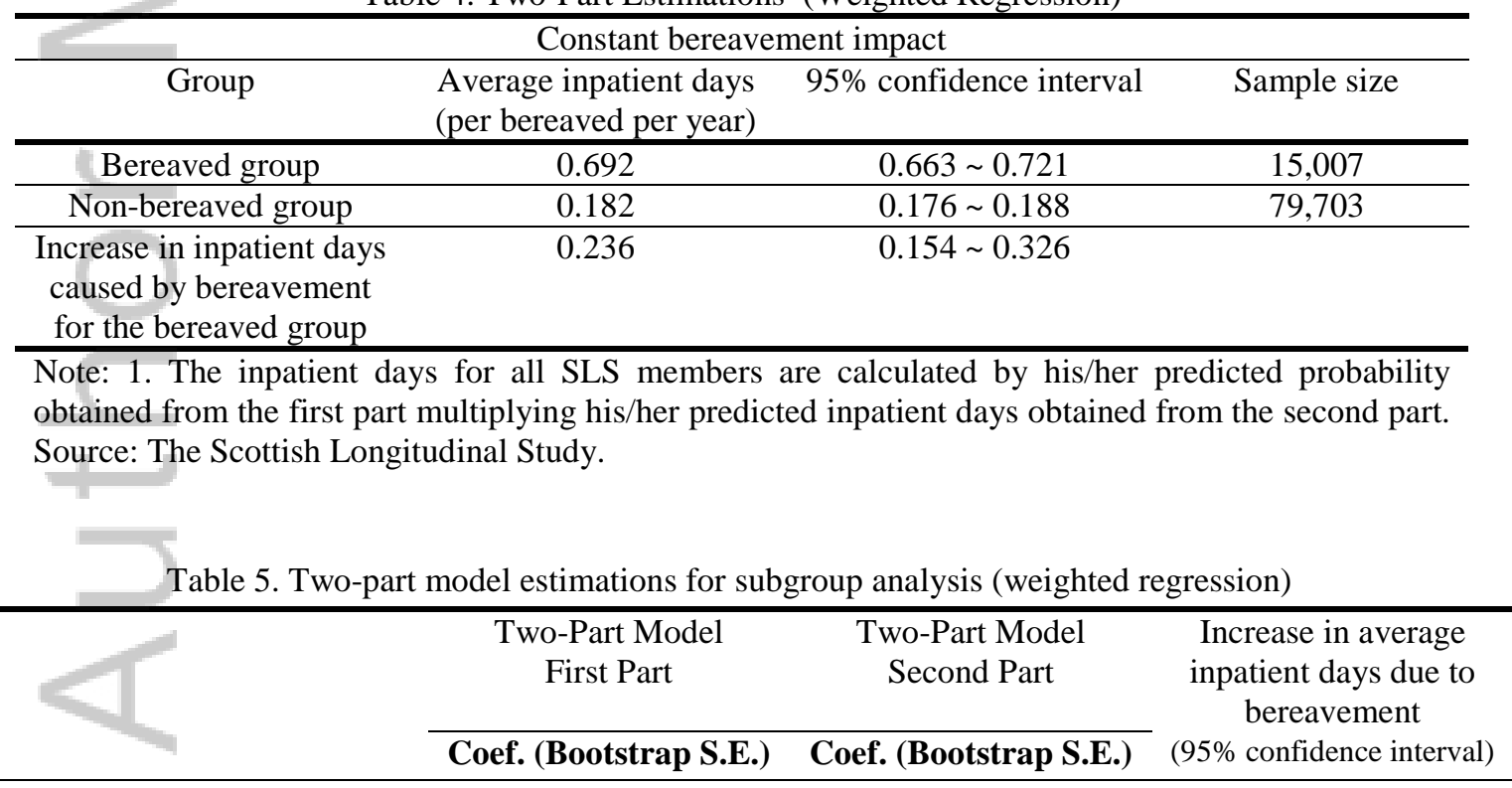




\begin{tabular}{lccc}
\hline Age & $0.056^{* * * *}(0.016)$ & $0.102^{* * *}(0.040)$ & $0.080(0.034 \sim 0.127)$ \\
Age I (age<75) & $0.149^{* * *}(0.029)$ & $0.131^{* * *}(0.044)$ & $0.612(0.360 \sim 0.863)$ \\
$\begin{array}{l}\text { Age II (Age>=75) } \\
\text { Initial household size }\end{array}$ & $0.128^{* * *}(0.019)$ & $0.094^{* * *}(0.038)$ & $0.332(0.198 \sim 0.466)$ \\
$\begin{array}{l}\text { Household I (a couple only, } \\
\text { size=2) }\end{array}$ & $0.068^{* * *}(0.021)$ & $0.106^{* * *}(0.045)$ & $0.114(0.039 \sim 0.188)$ \\
$\begin{array}{l}\text { Household II (size>2) } \\
\text { Cause of death of spouse }\end{array}$ & $0.115^{* * *}(0.050)$ & $0.268(0.130 \sim 0.406)$ \\
$\begin{array}{l}\text { Cancer } \\
\text { Accident and violence }\end{array}$ & $0.147(0.146)$ & $0.273(0.221)$ & $0.273(-0.218 \sim 0.765)$ \\
\hline
\end{tabular}

Note: 1. The values presented in the Two-part model are the coefficient of SB*Post. 2. The number of the bereaved whose spouse died in accident and violence defined in ICD-9 is 117. 3. ${ }^{*} p<0.10,{ }^{* * *} p<0.05,{ }^{* * *} p<0.01$. Source: The Scottish Longitudinal Study.

Table A1. Logit and kernel regressions for propensity score

\begin{tabular}{|c|c|c|}
\hline & $\begin{array}{c}\text { Logit } \\
\text { Coef. (Bootstrap S.E.) }\end{array}$ & $\begin{array}{c}\text { Kernel } \\
\text { Coef. (Bootstrap S.E.) }\end{array}$ \\
\hline Male & $0.623^{* * *}(0.028)$ & $-0.255^{* * * *}(0.015)$ \\
\hline Age & $0.020^{* * *}(0.003)$ & $-0.004^{* *}(0.002)$ \\
\hline Ethnicity (ref. Non-white) & & \\
\hline White & $-1.076^{* * * *}(0.226)$ & $0.530^{* * * *}(0.109)$ \\
\hline $\begin{array}{l}\text { Education (ref. No higher degr } \\
\text { qualification) }\end{array}$ & & \\
\hline First degree & $0.373^{* * * *}(0.056)$ & $-0.186^{* * * *}(0.029)$ \\
\hline Other higher qualification & $0.230^{* * * *}(0.047)$ & $-0.122^{* * * *}(0.025)$ \\
\hline Long-term illness & $0.157^{* * *}(0.029)$ & $0.018(0.017)$ \\
\hline $\begin{array}{l}\text { Social class based on occupatio } \\
\text { Managerial and technical occu }\end{array}$ & & \\
\hline Professional occupations & $0.069(0.090)$ & $-0.048(0.048)$ \\
\hline Skilled non-manual occupations & $0.054(0.039))$ & $-0.0003(0.021)$ \\
\hline Skilled manual occupations & $-0.219^{* * * *}(0.043)$ & $0.132^{* * *}(0.023)$ \\
\hline Partly skilled occupations & $-0.133^{* * *}(0.043)$ & $0.096^{* * *}(0.023)$ \\
\hline Unskilled occupations & $-0.305^{* * *}(0.045)$ & $0.201^{* * *}(0.025)$ \\
\hline Others & $0.132^{* * *}(0.037)$ & $0.029(0.021)$ \\
\hline Age of spouse & $-0.107^{* * * *}(0.003)$ & $\left.0.058^{* * *}(0.002)\right)$ \\
\hline
\end{tabular}

Table A2. The differences in probability of hospitalisation across whole pre-bereavement and postbereavement period (weighted regression)

\begin{tabular}{lccc}
\hline \multirow{2}{*}{ Panel Estimation } & \multicolumn{3}{c}{ Population-averaged } \\
\cline { 2 - 4 } & Total samples & Male & Female \\
\cline { 2 - 4 } & $\begin{array}{c}\text { Marginal effect } \\
\text { (Bootstrap S.E.) }\end{array}$ & $\begin{array}{c}\text { Marginal effect } \\
\text { (Bootstrap S.E.) }\end{array}$ & $\begin{array}{c}\text { Marginal effect } \\
\text { (Bootstrap S.E.) }\end{array}$ \\
\hline $\begin{array}{l}\text { Years prior to bereavement*SB } \\
7^{\text {th }} \text { year*SB }\end{array}$ & $-0.003(0.005)$ & $-0.003(0.008)$ & $-0.002(0.007)$ \\
$6^{\text {th }}$ year*SB & $-0.006(0.005)$ & $-0.007(0.008)$ & $-0.006(0.007)$
\end{tabular}




\begin{tabular}{lccc}
$5^{\text {th }}$ year*SB & $-0.002(0.006)$ & $0.001(0.007)$ & $-0.003(0.008)$ \\
$4^{\text {th }}$ year*SB & $-0.004(0.006)$ & $0.001(0.008)$ & $-0.007(0.007)$ \\
$3^{\text {rd }}$ year*SB & $-0.007(0.005)$ & $-0.001(0.008)$ & $-0.011(0.007)$ \\
$2^{\text {nd }}$ year*SB & $-0.006(0.005)$ & $-0.009(0.008)$ & $-0.003(0.008)$ \\
$1^{\text {st }}$ year*SB & $-0.003(0.006)$ & $-0.005(0.008)$ & $-0.002(0.008)$ \\
Bereavement year*SB & $0.012^{* *}(0.005)$ & $0.017^{* *}(0.007)$ & $0.009(0.007)$ \\
Years after bereavement*SB & & & \\
$1^{\text {st }}$ year*SB & $0.024^{* * *}(0.005)$ & $0.030^{* * *}(0.007)$ & $0.021^{* * * *}(0.007)$ \\
$2^{\text {nd }}$ year*SB & $0.021^{* * *}(0.006)$ & $0.021^{* *}(0.009)$ & $0.021^{* * *}(0.006)$ \\
$3^{\text {rd }}$ year*SB & $0.017^{* * *}(0.006)$ & $0.026^{* * *}(0.009)$ & $0.012^{*}(0.007)$ \\
$4^{\text {th }}$ year*SB & $0.022^{* * *}(0.006)$ & $0.032^{* * *}(0.010)$ & $0.018^{* *}(0.007)$ \\
$5^{\text {th }}$ year*SB & $0.011(0.007)$ & $0.015(0.011)$ & $0.010(0.009)$ \\
$6^{\text {th }}$ year*SB & $0.024^{* * *}(0.007)$ & $0.035^{* * *}(0.012)$ & $0.019^{* *}(0.009)$ \\
$7^{\text {th }}$ year*SB & $0.022^{* * *}(0.007)$ & $0.030^{* *}(0.012)$ & $0.019^{* *}(0.009)$ \\
\hline Sample size & $1,709,511$ & 829,113 & 880,398
\end{tabular}

Note: 1 . The other control variables in this regression are shown in Table 4 but SB, Post, and SB*Post are not included. 2. The dummy variables for each year pre- and post-bereavement are also controlled but not shown in the table. 3 . $\mathrm{p}<0.10,{ }^{* *} \mathrm{p}<0.05,{ }^{* * *} \mathrm{p}<0.01$. Source: The Scottish Longitudinal Study.

Table A3. The differences in log days of hospitalisation across whole pre-bereavement and postbereavement period (weighted regression)

\begin{tabular}{|c|c|c|c|}
\hline \multirow{3}{*}{ Panel Estimation } & \multicolumn{3}{|c|}{ Population-averaged } \\
\hline & Total samples & Male & Female \\
\hline & $\begin{array}{c}\text { Coef. } \\
\text { (Bootstrap S.E.) }\end{array}$ & $\begin{array}{c}\text { Coef. } \\
\text { (Bootstrap S.E.) }\end{array}$ & $\begin{array}{c}\text { Coef. } \\
\text { (Bootstrap S.E.) }\end{array}$ \\
\hline \multicolumn{4}{|c|}{ Years prior to bereavement*SB } \\
\hline $7^{\text {th }}$ year*SB & $-0.060(0.047)$ & $-0.030(0.071)$ & $-0.086(0.062)$ \\
\hline $6^{\text {th }}$ year*SB & $0.042(0.050)$ & $-0.020(0.075)$ & $0.081(0.066)$ \\
\hline $5^{\text {th }}$ year* $\mathrm{SB}$ & $0.011(0.047)$ & $0.127^{*}(0.067)$ & $-0.079(0.068)$ \\
\hline $4^{\text {th }}$ year*SB & $0.017(0.049)$ & $0.094(0.078)$ & $-0.034(0.064)$ \\
\hline $3^{\text {rd }}$ year* $\mathrm{SB}$ & $0.050(0.044)$ & $0.048(0.076)$ & $0.051(0.056)$ \\
\hline $2^{\text {nd }}$ year*SB & $-0.034(0.047)$ & $0.024(0.069)$ & $-0.074(0.061)$ \\
\hline $1^{\text {st }}$ year*SB & $-0.053(0.046)$ & $-0.134^{* *}(0.067)$ & $-0.001(0.058)$ \\
\hline Bereavement year*SB & $0.037(0.049)$ & $0.086(0.075)$ & $-0.009(0.066)$ \\
\hline \multicolumn{4}{|c|}{ Years after bereavement*SB } \\
\hline $1^{\text {st }}$ year*SB & $0.007(0.050)$ & $0.083(0.071)$ & $-0.052(0.068)$ \\
\hline $2^{\text {nd }}$ year* $\mathrm{SB}$ & $0.089(0.055)$ & $0.133(0.083)$ & $0.054(0.078)$ \\
\hline $3^{\text {rd }}$ year*SB & $0.094^{*}(0.050)$ & $0.176^{* *}(0.085)$ & $0.036(0.067)$ \\
\hline $4^{\text {th }}$ year*SB & $0.072(0.050)$ & $0.106(0.088)$ & $0.049(0.069)$ \\
\hline $5^{\text {th }}$ year*SB & $0.067(0.061)$ & $0.144(0.109)$ & $0.028(0.073)$ \\
\hline $6^{\text {th }}$ year*SB & $0.060^{*}(0.068)$ & $0.136(0.103)$ & $0.008(0.087)$ \\
\hline $7^{\text {th }}$ year*SB & $0.129(0.068)$ & $0.156(0.111)$ & $0.107(0.088)$ \\
\hline Sample size (Person years) & 227,364 & 110,272 & 117,092 \\
\hline
\end{tabular}

Note: 1 . The other control variables in this regression are shown in Table 4 but SB, Post, and SB*Post are not included. 2. The dummy variables for each year pre- and post-bereavement are also controlled but not shown in the table. 3 . " $\mathrm{p}<0.10,{ }^{* *} \mathrm{p}<0.05,{ }^{* * *} \mathrm{p}<0.01$. Source: The Scottish Longitudinal Study. 
Table A4. Two-Part Model Estimations (Weighted Regression)

\begin{tabular}{|c|c|c|c|c|}
\hline \multirow{3}{*}{ Panel Estimation } & \multicolumn{2}{|c|}{ First Part } & \multicolumn{2}{|c|}{ Second Part } \\
\hline & \multicolumn{4}{|c|}{ Population-averaged } \\
\hline & \multicolumn{2}{|c|}{ Coef. (Bootstrap S.E.) } & \multicolumn{2}{|c|}{ Coef. (Bootstrap S.E.) } \\
\hline SB (Spousal bereavement) & -0.006 & $(0.013)$ & -0.027 & $(0.021)$ \\
\hline Post (Post bereavement) & $0.093^{* * *}$ & $(0.011)$ & $0.262^{* * *}$ & $(0.022)$ \\
\hline SB*Post & $0.109^{* * *}$ & $(0.017)$ & $0.098^{* * *}$ & $(0.031)$ \\
\hline Age & $-0.009^{* * *}$ & $(0.003)$ & $-0.045^{* * *}$ & $(0.005)$ \\
\hline Square of age & $0.0002^{* * *}$ & $(0.00003)$ & $0.001^{* * *}$ & $(0.00004)$ \\
\hline Male & $0.104^{* * *}$ & $(0.011)$ & -0.004 & $(0.021)$ \\
\hline \multicolumn{5}{|l|}{ Ethnicity (ref. Non-white) } \\
\hline White & -0.071 & $(0.087)$ & -0.005 & $(0.115)$ \\
\hline \multicolumn{5}{|l|}{$\begin{array}{l}\text { Education (ref. No higher degree or } \\
\text { qualification) }\end{array}$} \\
\hline First degree & $-0.141^{* * *}$ & $(0.028)$ & $-0.106^{* *}$ & $(0.044)$ \\
\hline Other higher qualification & $-0.064^{* *}$ & $(0.026)$ & $-0.102^{* * *}$ & $(0.036)$ \\
\hline Long-term illness & $0.283^{* * *}$ & $(0.017)$ & $0.251^{* * *}$ & $(0.023)$ \\
\hline \multicolumn{5}{|l|}{$\begin{array}{l}\text { Social class based on occupations (ref. } \\
\text { Managerial and technical occupations) }\end{array}$} \\
\hline Professional occupations & 0.025 & $(0.047)$ & 0.008 & $(0.060)$ \\
\hline Skilled non-manual occupations & -0.022 & $(0.021)$ & -0.032 & $(0.032)$ \\
\hline Skilled manual occupations & 0.012 & $(0.022)$ & $0.065^{* *}$ & $(0.032)$ \\
\hline Partly skilled occupations & 0.031 & $(0.021)$ & $0.058^{* *}$ & $(0.032)$ \\
\hline Unskilled occupations & $0.044^{*}$ & $(0.024)$ & $0.100^{* * *}$ & $(0.035)$ \\
\hline Others & 0.018 & $(0.020)$ & $0.121^{* * *}$ & $(0.028)$ \\
\hline Year dummy variables are controlled & \multicolumn{2}{|c|}{ Yes } & \multicolumn{2}{|r|}{ Yes } \\
\hline Sample size & \multicolumn{2}{|c|}{$1,708,584$} & \multicolumn{2}{|c|}{227,494} \\
\hline
\end{tabular}




\begin{abstract}
This paper estimates the impact of spousal bereavement on hospital inpatient use for the surviving bereaved by following the experience of 94,272 married Scottish individuals from 1991 until 2009 using a difference-in-difference model. We also consider the sample selection issues related to differences in survival between the bereaved and non-bereaved using a simple Cox Proportional-Hazard model. Before conducting these estimations, propensity score approaches are used to re-weight the non-bereaved to generate a more random-like comparison sample for the bereaved.

We find that those bereaved who survive are both more likely to be admitted and to stay longer in hospital than a comparable non-bereaved cohort. Bereavement is estimated to induce on average an extra 0.24 (95\% CI: $0.154 \sim 0.326$ ) hospital inpatient days per year. Similar to previous studies, we estimate the bereaved have an $19.2 \%$ (95\% CI: $12.5 \%$ 26.3\%) higher mortality rate than the comparable non-bereaved cohort.
\end{abstract}

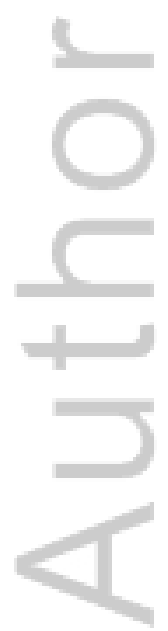

This article is protected by copyright. All rights reserved. 


\section{University Library}

\section{- M M N E R VA A gateway to Melbourne's research publications}

Minerva Access is the Institutional Repository of The University of Melbourne

Author/s:

Tseng, F-M;Petrie, D;Wang, S;Macduff, C;Stephen, Al

Title:

The impact of spousal bereavement on hospitalisations: Evidence from the Scottish Longitudinal Study

Date:

2018-02-01

Citation:

Tseng, F. -M., Petrie, D., Wang, S., Macduff, C. \& Stephen, A. I. (2018). The impact of spousal bereavement on hospitalisations: Evidence from the Scottish Longitudinal Study. HEALTH ECONOMICS, 27 (2), pp.E120-E138. https://doi.org/10.1002/hec.3573.

Persistent Link:

http://hdl.handle.net/11343/293348 